Journal of Engineering and Applied Sciences 15 (6): 1508-1514, 2020

ISSN: 1816-949X

(C) Medwell Journals, 2020

\title{
Enhancing R Control Chart Performance in Monitoring Process Dispersion using Scaled Weighted Variance Method for Skewed Populations
}

\author{
${ }^{1}$ Abdu Atta, ${ }^{2}$ Majed Shoraim, ${ }^{3}$ Sharipah Yahya, ${ }^{4}$ Ali Abuzaid and ${ }^{1}$ Esam Mahdi \\ ${ }^{1}$ Department of Mathematics, Statistics and Physics, School of Arts and Sciences, \\ Qatar University, Doha, Qatar \\ ${ }^{2}$ Department of Economics and Political Sciences, College of Commerce and Economics, \\ Hodeidah University, Hodeidah, Yemen \\ ${ }^{3}$ Department of Mathematics and Statistics, School of Quantitative Sciences, \\ Universiti Utara Malaysia, Sintok, Malaysia \\ ${ }^{4}$ Department of Mathematics, Faculty of Science, Al-Azhar University, Gaza, Palestine
}

\begin{abstract}
This study improves the performance of R control chart for monitoring process dispersion of skewed populations using scaled weighted variance method. This control chart, called Scaled Weighted Variance R control chart (SWV-R) hereafter, the SWV-R control chart compared with Skewness Correction R chart (SC-R) and Weighted Variance R chart (WV-R) in terms of false alarm. In terms of probability of detection rates the proposed SWV-R chart is compared with R chart of the exact method, SC-R and WV-R control charts. The proposed SWV-R control chart reduces to the Shewhart $\mathrm{R}$ control chart when the underlying distribution is symmetric. An illustrative example is given to show how the proposed SWV-R control chart is constructed and works simulations study show that the proposed SWV-R control chart has the lower false alarm rates than the SC-R and WV-R control charts, when the underlying distributions are Weibull and gamma. In terms of the probability of detection rates, the proposed SWV-R control chart is closer to R control chart with the exact method than WV-R and almost the same performance as SC-R chart.
\end{abstract}

Key words: R control chart, skewed population, scaled weighted variance method, SWV-R, WV-R, SC-R

\section{INTRODUCTION}

The control charts for variables data such as the $\overline{\mathrm{X}}$, EWMA, CUSUM, S and R control charts all depend on the assumption that the distribution of a quality characteristic is normal or approximately normal. However, in many situations, the normality assumption is usually violated. When the underlying distribution is non-normal, three approaches are presently employed to deal with this problem. The first approach is to increase the sample size until the sample mean is approximately normally distributed. The second approach is to transform the original data, so that, the transformed data have an approximate normal distribution. The last approach is to use heuristic methods to design control charts such as the $\bar{X}$ and R charts based on the Weighted Variance (WV) method proposed by Bai and Choi (1995), $\overline{\mathrm{X}}$ control chart using Scaled Weighted Variance (SWV- $\overline{\mathrm{X}}$ ) chart proposed by Castagliola (2000), the $\bar{X}$, EWMA and CUSUM charts based on the Weighted Standard Deviation (WSD) method suggested by Chang and Bai (2001), the $\bar{X}$ and $R$ charts based on the Skewness Correction (SC) method presented by Chan and Cui
(2003), a multivariate synthetic control chart for monitoring the process mean vector of skewed populations using weighted standard deviations suggested by Khoo et al. (2009b), a multivariate EWMA control chart using weighted variance method by Atta et al. (2014) and comparing the Median Run Length (MRL) performances of the Max-EWMA and Max-DEWMA control charts for skewed distributions by Teh et al. (2014). Other works that deal with univariate control charts for skewed distributions include that of Wu (1996), Nichols and Padgett (2005), Tsai (2007), Dou and Sa (2002), Chen (2004) and Yourstone and Zimmer (1992). In this study, the R control chart is developed by using the Scaled Weighted Variance (SWV) method suggested by Castagliola (2000). The proposed SWV-R control chart provides asymmetric limits in accordance with the direction and degree of skewness by using different variances in computing the upper and lower limits.

\section{MATERIALS AND METHODS}

The Weighted Variance (WV) method: The WV procedure splits a skewed distribution into two parts at its mean where each part is used to create a new

Corresponding Author: Abdu Atta, Department of Mathematics, Statistics and Physics, School of Arts and Sciences, Qatar University, Doha, Qatar 
symmetric distribution. The two new symmetric distributions are used to set up the limits of the chart Bai and Choi (1995).

Specifically, one of the two new distributions is used to compute the upper control limit while the other is used to compute the lower control limit of the WV control chart. Since, the WV method uses a multiple of the standard deviation to establish the control limits, it requires determination of the standard deviations of the two new symmetrical distributions. Choobineh and Ballard (1987) developed a method to approximate the variance of the two distributionsas follows:

Let $\varphi($.$) and \Phi($.$) denote the standard normal, \mathrm{N}(0$, 1), probability density function (pdf) and cdf, respectively. Let $\mathrm{f}(\mathrm{x})$ be pdf of quality characteristic $X$, from a skewed distribution; $\mu_{\mathrm{X}}$ and $\sigma_{\mathrm{X}}$ be the mean and standard deviation of $X$, respectively and $P_{X}=P\left(X \leq \mu_{X}\right)$. This method is based on the idea that the probability density function $f(x)$ can be split into two new symmetrical functions, $\mathrm{f}_{\mathrm{L}}(\mathrm{x})$ and $\mathrm{f}_{\mathrm{U}}(\mathrm{x})$ having the same mean $\mu_{\mathrm{X}}$ but different variances, $\sigma_{\mathrm{L}}{ }^{2}$ for $\mathrm{f}_{\mathrm{L}}(\mathrm{x})$ and $\sigma_{\mathrm{U}}{ }^{2}$ for $f_{U}(x)$. $f_{L}(x)$ and $f_{U}(x)$ are replaced by two normal distributions $\left.\varphi\left(\mathrm{x}, \mu_{\mathrm{X}}, \sigma_{\mathrm{L}}\right)=\varphi\left[\left(\mathrm{x}, \mu_{\mathrm{x}}\right) \sigma_{\mathrm{L}}^{-1}\right)\right] / \sigma_{\mathrm{L}}$ and $\varphi\left(\mathrm{x}, \mu_{\mathrm{X}}\right.$, $\left.\left.\sigma_{U}\right)=\varphi\left[\left(\mathrm{x}, \mu_{\mathrm{X}}\right) \sigma_{\mathrm{U}}{ }^{-1}\right)\right] / \sigma_{\mathrm{U}}$ having the same mean $\mu_{\mathrm{X}}$ and variances $\sigma_{\mathrm{L}}{ }^{2}$ and $\sigma_{\mathrm{U}}{ }^{2}$, respectively. This differs from the standard $\mathrm{R}$ control chart in that the standard deviation is multiplied by two different factors. One factor is used for the Upper Control Limit (UCL) while the other is used for the Lower Control Limit (LCL). Assume that $\mathrm{P}_{\mathrm{X}}=$ $\mathrm{P}\left(\mathrm{X} \leq \mu_{\mathrm{X}}\right)$ is the probability that random variable $\mathrm{X}$ is less than or equal to its mean $\mu_{\mathrm{X}}$. Then the UCL factor is $\sqrt{2 \mathrm{P}_{\mathrm{X}}}$ and the LCL factor is $\sqrt{2\left(1-P_{x}\right)}$ (for more details see Choobineh and Ballard (1987).

The WV-R control chart suggested by Bai and Choi (1995) is set up by plotting the sample ranges, $R_{i}$ for $i=1$, $2, \ldots$, based on the following limits:

$$
\mathrm{UCL}_{\mathrm{WV}-\mathrm{R}}=\mu_{\mathrm{R}}+3 \sigma_{\mathrm{R}} \sqrt{2 \mathrm{P}_{\mathrm{x}}}
$$

and:

$$
\mathrm{LCL}_{\mathrm{WV}-\mathrm{R}}=\mu_{\mathrm{R}}-3 \sigma_{\mathrm{R}} \sqrt{2\left(1-\mathrm{P}_{\mathrm{X}}\right)}
$$

where, $\mu_{R}$ and $\sigma_{R}$ are the mean and standard deviation of $R$, respectively. Note that when $P_{X}=1 / 2$ the WV-R control chart reduces to the standard $\mathrm{R}$ control chart. If the process parameters are unknown, the limits of the WV-R are:

$$
\mathrm{UCL}_{\mathrm{wV}-\mathrm{R}}=\overline{\mathrm{R}}\left[1+3 \frac{\mathrm{d}_{3}^{\prime}}{\mathrm{d}_{2}} \sqrt{2\left(1-\hat{\mathrm{P}}_{\mathrm{X}}\right)}\right]=\mathrm{VU}_{\mathrm{L}} \overline{\mathrm{R}}
$$

and:

$$
\mathrm{LCL}_{\mathrm{WV}-\mathrm{R}}=\overline{\mathrm{R}}\left[1-3 \frac{\mathrm{d}_{3}^{\prime}}{\mathrm{d}_{2}^{\prime}} \sqrt{2\left(1-\hat{\mathrm{P}}_{\mathrm{x}}\right)}\right]^{+}=\mathrm{V}_{\mathrm{L}} \overline{\mathrm{R}}
$$

here, $\mathrm{d}_{2}{ }^{\prime}$ and $\mathrm{d}_{3}{ }^{\prime}$ are control limits constants given in Bai and Choi (1995), $\bar{R}$ was the average of the sample ranges estimated from $r$ preliminary subgroups and:

$$
\hat{\mathrm{P}}_{\mathrm{X}}=\frac{\sum_{\mathrm{i}=1}^{\mathrm{m}} \sum_{\mathrm{j}=1}^{\mathrm{n}} \mathrm{I}\left(\overline{\bar{X}}-\mathrm{X}_{\mathrm{ij}}\right)}{\mathrm{m} \times \mathrm{n}}
$$

where, $\mathrm{m}$ and $\mathrm{n}$ are the number of samples in the preliminary data set and the sample size, respectively and $\mathrm{I}(\mathrm{x})=1$ if $\mathrm{x}^{3} \geq 0$ and $\mathrm{I}(\mathrm{x})=0$, otherwise.

Skewness Correction (SC) method: Chan and Cui (2003) proposed the Sc and R charts using Skewness Correction (SC) Method chart based on the Cornish-Fisher expansion. The limits of the SC-R chart are given by:

$$
\mathrm{UCL}_{\mathrm{SC}-\mathrm{R}}=\mu_{\mathrm{R}}+\left(3+\frac{4 \alpha_{3}(\mathrm{R})}{1+0.2 \alpha_{3}^{2}(\mathrm{R})}\right) \sigma_{\mathrm{R}}
$$

and:

$$
\mathrm{LCL}=\left[\mu_{\mathrm{R}}+\left(-3+\frac{4 \alpha_{3}(\mathrm{R})}{1+0.2 \alpha_{3}^{2}(\mathrm{R})}\right) \sigma_{\mathrm{R}}\right]^{+}
$$

Here, $\alpha_{3}(R)$ denotes the skewness of $R$. When the exact values of the process parameters are unknown, the control limits of the SC-R chart are Chan and Cui (2003):

$$
\mathrm{UCL}_{\mathrm{SC}-\mathrm{R}}=\left[1+\left(3+\mathrm{d}_{4}^{*}\right) \frac{\mathrm{d}_{3}^{*}}{\mathrm{~d}_{2}^{*}}\right] \overline{\mathrm{R}}
$$

and:

$$
\mathrm{LCL}_{\mathrm{SC}-\mathrm{R}}=\left[1+\left(-3+\mathrm{d}_{4}^{*}\right) \frac{\mathrm{d}_{3}^{*}}{\mathrm{~d}_{2}^{*}}\right]^{+} \overline{\mathrm{R}}
$$

where, $\mathrm{d}_{4}^{*}=\frac{4 \hat{\alpha}_{3}(\mathrm{R})}{1+0.2 \hat{\alpha}_{3}^{2}(\mathrm{R})}, \overline{\mathrm{R}}$ is the average sample ranges and values of $\mathrm{d}_{2}{ }^{*}$ and $\mathrm{d}_{3}{ }^{*}$ are given in Chan and Cui (2003).

Scaled Weighted Variance (SWV) method: Castagliola (2000) suggested an alternative approach, called the scaled weighted variance method to improve the performance of the weighted variance method. The functions $\mathrm{f}_{\mathrm{L}}(\mathrm{x})$ and $\mathrm{f}_{\mathrm{U}}(\mathrm{x})$ are not simply replaced by two normal probability density distributions $\varphi(\mathrm{x}$, $\left.\mu_{\mathrm{X}}, \sigma_{\mathrm{L}}\right)$ and $\varphi\left(\mathrm{x}, \mu_{\mathrm{X}}, \sigma_{\mathrm{U}}\right)$ but are replaced by two "bell-shaped" functions $\varphi\left(\mathrm{x}, \mu_{\mathrm{X}}, \sigma_{\mathrm{L}}, 2 \mathrm{P}_{\mathrm{X}}\right)$ and $\varphi(\mathrm{x}$, $\left.\mu_{\mathrm{X}}, \sigma_{\mathrm{U}}, 2\left(1-\mathrm{P}_{\mathrm{X}}\right)\right)$ centered on $\mu_{\mathrm{X}}$ having $\sigma_{\mathrm{L}}^{2}$ and $\sigma_{U}^{2}$ for second central moments and $2 \mathrm{P}_{\mathrm{X}}$ and $2\left(1-\mathrm{P}_{\mathrm{x}}\right)$ for areas. Castagliola (2000) defined the function $\varphi\left(x, \mu_{x}, t, k\right)$ as $\phi\left(x, \mu_{x}, t, k\right)=\frac{k^{3 / 2}}{t} \varphi\left(\frac{\left(x-\mu_{x}\right) \sqrt{k}}{t}\right)$. 
This function has the following required properties (Castagliola (2000)) for more details about the derivations:

$$
\begin{gathered}
\int_{-\infty}^{+\infty} \phi\left(\mathrm{x}, \mu_{\mathrm{x}}, \mathrm{t}, \mathrm{k}\right) \mathrm{dx}=\mathrm{k} \\
\int_{-\infty}^{+\infty}\left(\mathrm{x}-\mu_{\mathrm{x}}\right)^{2} \phi\left(\mathrm{x}, \mu_{\mathrm{x}}, \mathrm{t}, \mathrm{k}\right) \mathrm{dx}=\mathrm{t}^{2}
\end{gathered}
$$

Using $\varphi\left(\mathrm{x}, \mu_{\mathrm{X}}, \mathrm{t}, \mathrm{k}\right)$ instead of the probability density function $\varphi\left(x, \mu_{x}, t\right)$ gives new limits for the weighted variance $S$ control chart proposed by Khoo et al. (2009a). Here, the limits of the proposed Scaled Weighted Variance S control chart (SWV-S) are:

$$
\mathrm{LCL}_{\mathrm{SWV}-\mathrm{R}}=\mu_{\mathrm{R}}+\Phi^{-1}\left(1-\frac{\alpha}{4\left(1-\mathrm{P}_{\mathrm{X}}\right)}\right) \sqrt{\frac{\mathrm{P}_{\mathrm{x}}}{\left(1-\mathrm{P}_{\mathrm{x}}\right)}} \sigma_{\mathrm{R}}
$$

and:

$$
\mathrm{LCL}_{\mathrm{SWV}-\mathrm{R}}=\mu_{\mathrm{R}}+\Phi^{-1}\left(1-\frac{\alpha}{4 \mathrm{P}_{\mathrm{x}}}\right) \sqrt{\frac{\left(1-\mathrm{P}_{\mathrm{x}}\right)}{\mathrm{P}_{\mathrm{x}}}} \sigma_{\mathrm{R}}
$$

where, $\mu_{R}$ and $\sigma_{R}$ are the mean and standard deviation of the R, respectively and $\alpha$ is Type I error rate (False alarm). Note also that when $P_{X}=1 / 2$, the SWV-R control chart reduces to the Shewhart R control chart. If the process parameters are unknown, the control limits of the proposed SWV-R control chart are computed as follows:

$$
\mathrm{UCL}_{\mathrm{SWV}-\mathrm{R}}=\overline{\mathrm{R}}\left[1+\Phi^{-1}\left(1-\frac{\alpha}{4\left(1-\hat{\mathrm{P}}_{\mathrm{x}}\right)}\right) \frac{\mathrm{d}_{3}^{\prime}}{\mathrm{d}_{2}^{\prime}} \sqrt{\frac{\hat{\mathrm{P}}_{\mathrm{x}}}{\left(1-\hat{\mathrm{P}}_{\mathrm{x}}\right)}}\right]
$$

and:

$$
\mathrm{LCL}_{\mathrm{SWV}-\mathrm{R}}=\overline{\mathrm{R}}\left[1-\Phi^{-1}\left(1-\frac{\alpha}{4 \hat{\mathrm{P}}_{\mathrm{x}}}\right) \frac{\mathrm{d}_{3}^{\prime}}{\mathrm{d}_{2}^{\prime}} \sqrt{\frac{\left(1-\hat{\mathrm{P}}_{\mathrm{x}}\right)}{\hat{\mathrm{P}}_{\mathrm{x}}}}\right]^{+}
$$

Here, the constants $d_{2}{ }^{\prime}$ and $d_{3}{ }^{\prime}$ can be computed analytically or by numerical integration. Their parameters determined for each computed via. simulation using SAS software when the underlying distributions are skewed and $\overline{\mathrm{R}}=\frac{\sum_{\mathrm{i}=1}^{\mathrm{r}} \mathrm{R}_{\mathrm{i}}}{\mathrm{r}}$ is the average of the sample ranges estimated from r preliminary subgroups.

Exact method of $R$ chart for the exponential distribution: When the distribution is known, the control limits for a given Type I risk can sometimes be derived analytically. Here, we consider the case when the distribution is exponential with known parameter $\lambda=$ $\sigma_{0}$ (i.e., Weibull with $\beta=1$ ) (Chan and Cui (2003)) for more details. The density and distribution functions of $\mathrm{R}$ are:

$$
f(r)=\frac{n-1}{\sigma_{0}} e^{-r / \sigma_{0}}\left[1-e^{r / \sigma_{0}}\right]^{n-2}
$$

and:

$$
F(r)=\left[1-e^{-r / \sigma_{0}}\right]^{n-1}
$$

Respectively the mean and standard deviation of $\mathrm{R}$ can be derived analytically (Chan and Cui (2003)) and the value of skewness $\alpha_{3}$ can be obtained by numerical integration. The control limits $\mathrm{UCL}_{\mathrm{R}}$ and $\mathrm{LCL}_{\mathrm{R}}$ of the R charts by the exact methods can be then obtained. The control limits are the same as those in Section 2 with known parameters. But the observations in the subgroups

\begin{tabular}{|c|c|c|c|c|c|c|c|}
\hline \multirow[b]{2}{*}{ Sample ,i } & \multicolumn{5}{|c|}{ Observed values } & \multirow[b]{2}{*}{$\mathrm{R}_{\mathrm{i}}$} & \multirow[b]{2}{*}{$\overline{\mathrm{X}}_{\mathrm{i}}$} \\
\hline & $\mathrm{X}_{1}$ & $\mathrm{X}_{2}$ & $\mathrm{X}_{3}$ & $\mathrm{X}_{4}$ & $\mathrm{X}_{5}$ & & \\
\hline 1 & 36.34818 & 22.17544 & 6.859294 & 38.06268 & 56.00602 & 49.14672 & 31.89032 \\
\hline 2 & 3.803384 & 3.073572 & 108.6083 & 57.38147 & 39.00405 & 105.5347 & 42.37415 \\
\hline 3 & 53.68370 & 50.82171 & 139.9070 & 68.93220 & 1.715175 & 138.1918 & 63.01195 \\
\hline 4 & 69.88040 & 13.33184 & 11.46414 & 0.532185 & 2.836212 & 69.34822 & 19.60896 \\
\hline 5 & 9.754806 & 29.44874 & 31.30970 & 8.411457 & 13.05252 & 22.89824 & 18.39545 \\
\hline 6 & 13.69733 & 0.156438 & 22.04482 & 10.48240 & 63.68418 & 63.52774 & 22.01303 \\
\hline 7 & 0.731333 & 15.71949 & 47.42605 & 4.871906 & 37.75516 & 46.69472 & 21.30079 \\
\hline 8 & 10.46658 & 7.359650 & 0.744235 & 0.338600 & 192.5089 & 192.1703 & 42.28359 \\
\hline 9 & 27.92345 & 2.565996 & 24.89902 & 11.83283 & 1.356413 & 26.56704 & 13.71554 \\
\hline 10 & 48.25964 & 4.733874 & 52.36500 & 19.94588 & 3.989499 & 48.37550 & 25.85878 \\
\hline 11 & 45.54962 & 73.22100 & 19.48764 & 18.21503 & 119.6577 & 101.4427 & 55.22620 \\
\hline 12 & 5.089729 & 59.90313 & 14.41314 & 9.841913 & 63.70672 & 58.61699 & 30.59093 \\
\hline 13 & 10.48647 & 78.25828 & 37.88342 & 30.91023 & 149.9729 & 139.4865 & 61.50227 \\
\hline 14 & 9.184076 & 4.387413 & 5.775237 & 114.6605 & 24.35253 & 110.2731 & 31.67196 \\
\hline
\end{tabular}
are from the exponential distribution with the following density function:

$$
\frac{1}{\left(\lambda \sigma_{0}\right)} \mathrm{e}^{\frac{\left[\left((x-1-\lambda) \sigma_{0}\right)\right]}{\left(\lambda \sigma_{0}\right)}}, x \geq(1-\lambda) \sigma_{0}
$$

An illustrate example: The data in Table 1 are generated from a gamma distribution with shape parameter, $\beta=0.98$

Table 1: An example of illustration using simulated data from a skewed population (gamma distribution) 
Table 1: Continue

\begin{tabular}{|c|c|c|c|c|c|c|c|}
\hline \multirow[b]{2}{*}{ Sample ,i } & \multicolumn{5}{|c|}{ Observed values } & \multirow[b]{2}{*}{$\mathrm{R}_{\mathrm{i}}$} & \multirow[b]{2}{*}{$\overline{\mathrm{X}}_{\mathrm{i}}$} \\
\hline & $X_{1}$ & $X_{2}$ & $\mathrm{X}_{3}$ & $\mathrm{X}_{4}$ & $\mathrm{X}_{5}$ & & \\
\hline$\overline{15}$ & 10.29390 & 23.09588 & 5.604623 & 10.95006 & 51.29480 & 45.69018 & 20.24785 \\
\hline 16 & 58.14751 & 15.92276 & 42.08211 & 1.022873 & 47.96474 & 57.12463 & 33.02800 \\
\hline 17 & 77.80144 & 57.39865 & 37.56566 & 37.30812 & 119.8208 & 82.51272 & 65.97894 \\
\hline 18 & 18.38461 & 60.30539 & 38.73632 & 55.00603 & 50.30109 & 41.92078 & 44.54669 \\
\hline 19 & 53.69745 & 1.597253 & 33.21739 & 20.07705 & 8.381358 & 52.10020 & 23.39410 \\
\hline 20 & 28.38292 & 18.02485 & 24.47566 & 15.74064 & 52.77296 & 37.03232 & 27.87941 \\
\hline 21 & 104.7283 & 6.583657 & 15.66652 & 3.788275 & 8.947521 & 100.9400 & 27.94285 \\
\hline 22 & 21.29227 & 36.70789 & 74.14813 & 14.69886 & 33.40366 & 59.44927 & 36.05016 \\
\hline 23 & 11.31113 & 18.36397 & 13.27054 & 49.26539 & 0.007235 & 49.25815 & 18.44365 \\
\hline 24 & 6.521320 & 7.717710 & 2.481529 & 15.99499 & 66.52404 & 64.04251 & 19.84792 \\
\hline 25 & 30.31566 & 1.008256 & 3.476084 & 66.72805 & 42.92361 & 65.71980 & 28.89033 \\
\hline 26 & 24.93475 & 0.570747 & 3.297847 & 18.43215 & 23.09530 & 24.36400 & 14.06616 \\
\hline 27 & 53.42357 & 80.60140 & 31.23386 & 1.746260 & 15.61345 & 78.85514 & 36.52371 \\
\hline 28 & 19.82378 & 88.34585 & 9.922032 & 25.34298 & 19.09469 & 78.42382 & 32.50587 \\
\hline 29 & 12.80654 & 18.63652 & 7.658047 & 7.148106 & 35.75994 & 28.61183 & 16.40183 \\
\hline 30 & 24.91324 & 2.488491 & 16.33146 & 13.29951 & 3.479776 & 22.42475 & 12.10250 \\
\hline & & & & & & $\overline{\mathrm{R}}=68.69$ & $=31.24313$ \\
\hline
\end{tabular}

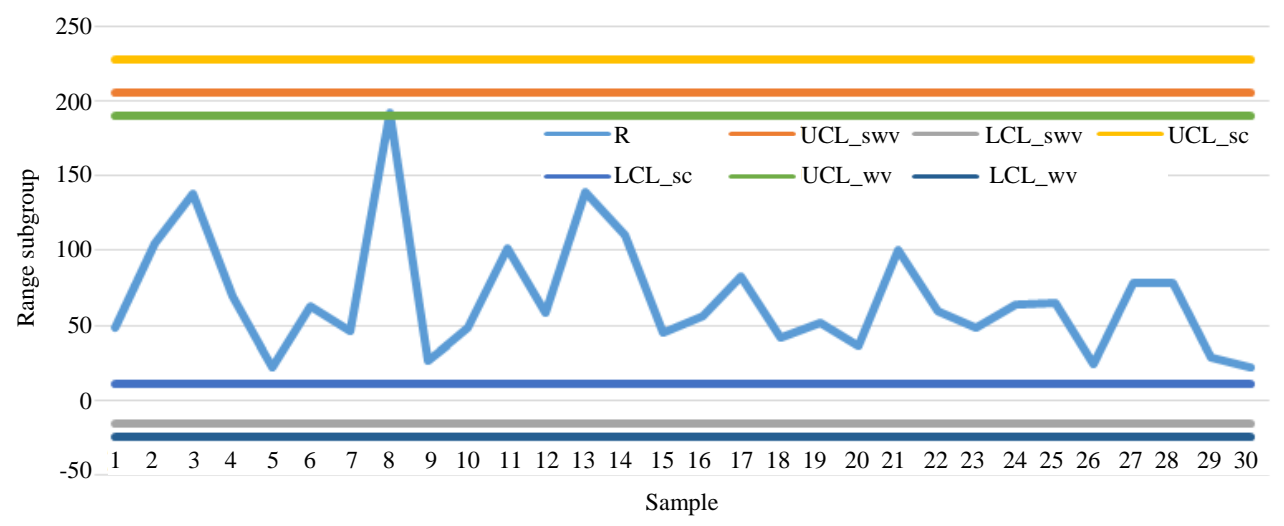

Fig. 1: R type control charts for the SWV, WV and SC methods using simulated data from distribution

and scale parameter, $\lambda=40.50$. The data consist of 150 skewed observations grouped into 30 subgroups of size $\mathrm{n}=5$ each. These data are supposed to correspond to an in-control process. Since, the shape parameter, $\beta$ is chosen to be 0.98 then the skewness, $\propto_{3}=2$. From these data, we compute, $\hat{\sigma}_{\mathrm{x}}=25.44, \hat{\mu}_{\mathrm{x}}=31.24, \mathrm{~d}_{2}{ }^{\prime}=2.21$, $\mathrm{d}_{3}{ }^{\prime}=1.16, \mathrm{~d}_{2}{ }^{*}=1.41$ and $\overline{\mathrm{R}}=68.69$. It is observed that 95 observations fall below. Thus, $\hat{\mathrm{P}}_{\mathrm{x}}=0.63$ using Eq. 5 . Consider that $\alpha=0.0027$, the SWV-R chart's control limits computed using Eq. 14 and 15 are equal to $\mathrm{UCL}_{\mathrm{SWV}-\mathrm{R}}=205.456$ and $\mathrm{LCL}_{\mathrm{SWV}-\mathrm{R}}=-16.127$. The control limits of SWV-R chart are compared with those obtained for the WV-R control limits using Eq. 3 and 4, $\mathrm{UCL}_{\mathrm{WV}-\mathrm{R}}=190.103$ andLCL $\mathrm{LV}_{\mathrm{WV}}=-24.356$ and the SC-R control limits which are computed using Eq. 8 and 9, UCL $\mathrm{SC}_{\mathrm{SC}}=227.690$ and $\mathrm{LCL}_{\mathrm{SC}-\mathrm{R}}=$ 11.363. From Figure 1, we observe that all points fall within control limits of the SWV-R and SC-R control charts indicating that the process is in-control while one points are outside the WV-R chart Upper control limit, potentially signaling a false alarm. To evaluate the performance of each of these charts, a simulation study is undertaken and the findings are further discussed.

\section{RESULTS AND DISCUSSION}

Performance evaluation and discussion of the proposed SWV-R control chart: The SWV-R control chart is compared with the SC-R and WV-R control chart for skewed data. A Monte Carlo simulation is conducted using SAS 9.4 to compute the false alarm rates and Probabilities of out-of-control detections. The false alarm rate of a control chart is defined as the proportion of subgroup points plotting beyond the limits of the chart, given that the process is actually in-control. On the contrary, the probability of out-of-control detection measures the ability of a chart in responding to a shift in the process and it represents the proportion of subgroup points plotting beyond the limits of the chart when the process has shifted. All the charts considered in this study are designed based on an in-control Average Run Length 
(ARL) of 370 or Type I error of 0.0027 . A shift in the process standard deviation is represented by $\sigma_{1}=\delta \sigma_{\mathrm{X}}$ where $\delta \in\{1.1,1.2,1.3,1.4,1.5,2.0,2.5,3.0,3.5,4.0$, $4.5\}$ is the magnitude of a shift in process standard deviation. The skewed distributions considered here are Weibull and gamma because they represent a wide variety of shapes from symmetric to highly skewed. For the sake of comparison, the standard normal distribution is also considered. For convenience, a scale parameter of one is used for the Weibull and gamma distributions. Note that $\mathrm{P}_{\mathrm{X}}$ for the Weibull and gamma distributions are:

$$
\mathrm{P}_{\mathrm{X}}=1-\exp \left[-\left(\Gamma\left(1+\frac{1}{\beta}\right)\right)^{\beta}\right]
$$

and:

$$
P_{x}=F(\gamma)
$$

Respectively where $\beta$ and $\gamma$ are the shape parameters . Here, $\Gamma($.) is the gamma function while $\mathrm{F}($.) is the gamma distribution functions, respectively. In the case of the false alarm rates, the skewness coefficients considered are $\alpha_{3} \in\{0.5,1.0,1.5,2.0,2.5,3.0\}$ while skewness coefficient, $\alpha_{3}=2$ is considered in the case of the probability of out-of-control detection. The sample sizes, $\mathrm{n} \in\{5,7,10\}$ are considered. The false alarm rate and probability of out-of-control detection are obtained based on 10000 simulation trials. The simulated results are tabulated in Table 2 and 3 for the false alarm rate in the cases of known and unknown parameters while probability of out-of-control detections are tabulated in Table 4-6, respectively where the smallest value are bolded. Table 2 and 3 show that the proposed SWV-R control chart has lower false alarm rate than the SC-R and WV-R control charts for almost all levels of

Table 2: False alarm rates of the SWV-R, SC-R and WV-R control charts for known parameters

\begin{tabular}{|c|c|c|c|c|c|c|c|c|c|c|}
\hline \multirow[b]{2}{*}{ Distribution } & \multirow[b]{2}{*}{$\alpha_{3}$} & \multicolumn{3}{|l|}{5} & \multicolumn{3}{|l|}{7} & \multicolumn{3}{|l|}{10} \\
\hline & & SWV-R & SC-R & WV-R & SWV-R & SC-R & WV-R & SWV-R & SC-R & WV-R \\
\hline $\begin{array}{l}\text { Normal } \\
\text { Weibull }\end{array}$ & 0.0 & 0.0064 & 0.0021 & 0.0241 & 0.0059 & 0.0025 & 0.0088 & 0.0055 & 0.0032 & 0.0047 \\
\hline 2.2266 & 0.5 & 0.0032 & 0.0018 & 0.0033 & 0.0025 & 0.0024 & 0.0032 & 0.0020 & 0.0024 & 0.0024 \\
\hline$\beta \quad 1.5688$ & 1.0 & 0.0045 & 0.0045 & 0.0058 & 0.0040 & 0.0057 & 0.0043 & 0.0036 & 0.0048 & 0.0040 \\
\hline 1.2123 & 1.5 & 0.0064 & 0.0099 & 0.0082 & 0.0058 & 0.0134 & 0.0067 & 0.0051 & 0.0085 & 0.0062 \\
\hline 0.9987 & 2.0 & 0.0082 & 0.0166 & 0.0103 & 0.0073 & 0.0246 & 0.0084 & 0.0062 & 0.0118 & 0.0073 \\
\hline 0.8598 & 2.5 & 0.0098 & 0.0222 & 0.0114 & 0.0089 & 0.0372 & 0.0099 & 0.0076 & 0.0143 & 0.0077 \\
\hline 0.7637 & 3.0 & 0.0108 & 0.0250 & 0.0118 & 0.0099 & 0.0436 & 0.0107 & 0.0083 & 0.0167 & 0.0083 \\
\hline \multicolumn{11}{|l|}{ gamma } \\
\hline 15.4 & 0.5 & 0.0060 & 0.0056 & 0.0063 & 0.0056 & 0.0041 & 0.0066 & 0.0052 & 0.0048 & 0.0057 \\
\hline 3.913 & 1.0 & 0.0066 & 0.0088 & 0.0085 & 0.0060 & 0.0072 & 0.0071 & 0.0057 & 0.0064 & 0.0069 \\
\hline$\alpha \quad 1.788$ & 1.5 & 0.0074 & 0.0097 & 0.0099 & 0.0067 & 0.0126 & 0.0076 & 0.0063 & 0.0086 & 0.0082 \\
\hline 0.983 & 2.0 & 0.0084 & 0.0149 & 0.0104 & 0.0072 & 0.0251 & 0.0083 & 0.0064 & 0.0118 & 0.0073 \\
\hline 0.648 & 2.5 & 0.0092 & 0.0198 & 0.0096 & 0.0078 & 0.0472 & 0.0096 & 0.0066 & 0.0157 & 0.0057 \\
\hline 0.442 & 3.0 & 0.0103 & 0.0225 & 0.0085 & 0.0083 & 0.0802 & 0.0110 & 0.0069 & 0.0208 & 0.0052 \\
\hline
\end{tabular}

Sample size (n)

Table 3: False Alarm rates of the SWV-R, SC-R and WV-R control charts for unknown parameters

\begin{tabular}{|c|c|c|c|c|c|c|c|c|c|c|}
\hline \multirow[b]{2}{*}{ Distribution } & \multirow[b]{2}{*}{$\alpha_{3}$} & \multicolumn{3}{|l|}{5} & \multicolumn{3}{|l|}{7} & \multicolumn{3}{|l|}{10} \\
\hline & & SWV-R & SC-R & WV-R & SWV-R & SC-R & WV-R & SWV-R & SC-R & WV-R \\
\hline normal & 0.0 & 0.0046 & 0.0045 & 0.0045 & 0.0044 & 0.0045 & 0.0044 & 0.0043 & 0.0041 & 0.0043 \\
\hline 3.6286 & 0.0 & 0.0029 & 0.0011 & 0.0029 & 0.0026 & 0.0020 & 0.0026 & 0.0026 & 0.0026 & 0.0026 \\
\hline 2.2266 & 0.5 & 0.0029 & 0.0029 & 0.0037 & 0.0030 & 0.0044 & 0.0036 & 0.0032 & 0.0059 & 0.0038 \\
\hline$\beta \quad 1.5688$ & 1.0 & 0.0040 & 0.0054 & 0.0057 & 0.0039 & 0.0076 & 0.0055 & 0.0039 & 0.0092 & 0.0055 \\
\hline 1.2123 & 1.5 & 0.0047 & 0.0059 & 0.0075 & 0.0045 & 0.0083 & 0.0071 & 0.0043 & 0.0108 & 0.0070 \\
\hline 0.9987 & 2.0 & 0.0052 & 0.0039 & 0.0089 & 0.0049 & 0.0070 & 0.0085 & 0.0046 & 0.0092 & 0.0081 \\
\hline 0.8598 & 2.5 & 0.0056 & 0.0050 & 0.0100 & 0.0052 & 0.0040 & 0.0094 & 0.0048 & 0.0058 & 0.0090 \\
\hline 0.7637 & 3.0 & 0.0058 & 0.0043 & 0.0108 & 0.0054 & 0.0039 & 0.0102 & 0.0049 & 0.0041 & 0.0096 \\
\hline \multicolumn{11}{|l|}{ gamma } \\
\hline 38000 & 0.0 & 0.0045 & 0.0014 & 0.0046 & 0.0044 & 0.0019 & 0.0044 & 0.0042 & 0.0024 & 0.0043 \\
\hline 15.4 & 0.5 & 0.0046 & 0.0023 & 0.0054 & 0.0045 & 0.0033 & 0.0052 & 0.0047 & 0.0045 & 0.0054 \\
\hline 3.913 & 1.0 & 0.0053 & 0.0045 & 0.0070 & 0.0052 & 0.0061 & 0.0070 & 0.0051 & 0.0071 & 0.0070 \\
\hline$\alpha \quad 1.788$ & 1.5 & 0.0054 & 0.0052 & 0.0082 & 0.0053 & 0.0070 & 0.0080 & 0.0050 & 0.0089 & 0.0077 \\
\hline 0.983 & 2.0 & 0.0051 & 0.0036 & 0.0087 & 0.0048 & 0.0063 & 0.0081 & 0.0045 & 0.0088 & 0.0081 \\
\hline 0.648 & 2.5 & 0.0046 & 0.0028 & 0.0089 & 0.0043 & 0.0040 & 0.0086 & 0.0040 & 0.0067 & 0.0082 \\
\hline 0.442 & 3.0 & 0.0043 & 0.0036 & 0.0094 & 0.0039 & 0.0052 & 0.0133 & 0.0036 & 0.0046 & 0.0084 \\
\hline
\end{tabular}
Sample size (n)

Bold values are significant 
Table 4: Probabilities of out-of-control of variant dispersion control charts, Weibull shape parameter $\beta=1, \mathrm{n}=5$

\begin{tabular}{lrrrr}
\hline $\mathrm{n}=5$ & & & & \\
- & & & \\
Distribution/ $\delta$ & SWV-R & Exact R-chart & SC-R & WV-R \\
\hline \multicolumn{4}{l}{ Weibull, $\boldsymbol{\beta}=\mathbf{1}$} \\
1.1 & (dalta) & & & \\
1.2 & 0.0097 & 0.0039 & 0.0061 & 0.0159 \\
1.3 & 0.0160 & 0.0062 & 0.0095 & 0.0250 \\
1.4 & 0.0244 & 0.0095 & 0.0143 & 0.0363 \\
1.5 & 0.0349 & 0.0143 & 0.0212 & 0.0504 \\
2.0 & 0.0477 & 0.0210 & 0.0303 & 0.0676 \\
2.5 & 0.1385 & 0.0745 & 0.0977 & 0.1770 \\
3.0 & 0.2542 & 0.1593 & 0.1962 & 0.3071 \\
3.5 & 0.3727 & 0.2571 & 0.3025 & 0.4292 \\
4.0 & 0.4796 & 0.3574 & 0.4078 & 0.5382 \\
4.5 & 0.5717 & 0.4496 & 0.5008 & 0.6265 \\
\hline
\end{tabular}

Table 5: Probabilities of out-of-control of variant dispersion control charts, Weibull shape parameter $\beta=1, n=7$

\begin{tabular}{|c|c|c|c|c|}
\hline \multicolumn{5}{|l|}{$\mathrm{n}=7$} \\
\hline Distribution/ $\delta$ & SWV-R & Exact R-chart & SC-R & WV-H \\
\hline \multicolumn{5}{|c|}{ Weibull, $\beta=1$ (dalta) } \\
\hline 1.1 & 0.0095 & 0.0038 & 0.0080 & $0.015 t$ \\
\hline 1.2 & 0.0162 & 0.0062 & 0.0109 & 0.025 \\
\hline 1.3 & 0.0254 & 0.0099 & 0.0160 & 0.0385 \\
\hline 1.4 & 0.0375 & 0.0154 & 0.0234 & 0.0546 \\
\hline 1.5 & 0.0518 & 0.0226 & 0.0329 & 0.0735 \\
\hline 2.0 & 0.1615 & 0.0880 & 0.1149 & 0.2070 \\
\hline 2.5 & 0.3040 & 0.1925 & 0.2354 & 0.3647 \\
\hline 3 & 0.4473 & 0.3160 & 0.3689 & 0.5121 \\
\hline 3.5 & 0.5716 & 0.4373 & 0.4929 & 0.633 \\
\hline 4.0 & 0.6722 & 0.5445 & 0.5989 & 0.7262 \\
\hline 4.5 & 0.7504 & 0.6362 & 0.6858 & 0.796 \\
\hline
\end{tabular}

Table 6: Probabilities of out- of- control of variant dispersion control charts, Weibull shape parameter $\beta=1, \mathrm{n}=10$

\begin{tabular}{|c|c|c|c|c|}
\hline Distribution/ $\delta$ & SWV-R & Exact R-chart & SC-R & WV-R \\
\hline \multicolumn{5}{|c|}{ Weibull, $\beta=1$ (dalta) } \\
\hline 1.1 & 0.0094 & 0.0037 & 0.0088 & 0.0155 \\
\hline 1.2 & 0.0165 & 0.0063 & 0.0114 & 0.0262 \\
\hline 1.3 & 0.0269 & 0.0106 & 0.0168 & 0.0407 \\
\hline 1.4 & 0.0404 & 0.0170 & 0.0251 & 0.0596 \\
\hline 1.5 & 0.0572 & 0.0256 & 0.0362 & 0.0817 \\
\hline 2.0 & 0.1883 & 0.1056 & 0.1344 & 0.2412 \\
\hline 2.5 & 0.3622 & 0.2373 & 0.2842 & 0.4315 \\
\hline 3 & 0.5296 & 0.3886 & 0.4441 & 0.6001 \\
\hline 3.5 & 0.5296 & 0.5333 & 0.5883 & 0.7302 \\
\hline 4.0 & 0.6691 & 0.6525 & 0.7025 & 0.8204 \\
\hline 4.5 & 0.7715 & 0.7471 & 0.7890 & 0.8819 \\
\hline
\end{tabular}

skewnesses and sample sizes, when the distributions are Weibull and gamma. Table 4-6 show that the probabilities of out-of-control detections of the proposed SWV-R and SC-R charts are close to those of the exact $\mathrm{R}$ chart than the WV-R control chart. In general, the proposed SWV-R control chart provides good performances in term of false alarm rate and probability of out-of-control detection for all levels of skewnesses, sample sizes and magnitudes of shifts.

\section{CONCLUSION}

In this study, we have proposed the SWV-R control chart for skewed populations. This proposed chart based on the scaled weighted variance method suggested by Castagliola (2000). The proposed SWV-R control chart reduces to the Shewhart $\mathrm{R}$ control chart when the underlying population has a normal distribution. Our simulation study on the false alarm rate indicates that the SWV-R control chart provides lower false alarm rates than those of SC-R and WV-R control charts for all levels of skewnesses and sample sizes. The proposed SWV-R control chart offers considerable improvement over the SC-R and WV-R control charts when it is desirable for the false alarm rate to be closed to the conventional 0.0027. In the case of the probability of out-of-control detections, the simulation results show that the said probabilities of the proposed SWV-R control chart are closer to the chart constructed by exact $\mathrm{R}$ chart than the WV-R control charts. The findings are based on the SWV-R method instead of relying on the SC-R and $\mathrm{WV}-\mathrm{R}$. Hence, the SWV-R chart can act as a favorable substitute to the existing SC-R and WV-R control charts in the evaluation of the speed of a chart to detect shifts in process dispersion, when the underlying distribution is skewed.

\section{REFERENCES}

Atta, A.M.A., M.H.A. Shoraim and S. Yahaya, 2014. A multivariate EWMA control chart for skewed populations using weighted variance method. Int. Res. J. Sci. Eng., 2: 191-202.

Bai, D.S. and I.S. Choi, 1995. X and R control charts for skewed populations. J. Qual. Technol., 27: 120-131.

Castagliola, P., 2000. Control chart for skewed populations using a scaled weighted variance method. Int. J. Reliab. Qual. Saf. Eng., 7: 237-252.

Chan, L.K. and H.J. Cui, 2003. Skewness correction $\mathrm{X}^{-}$ and $\mathrm{R}$ charts for skewed distributions. Nav. Res. Logist. (NRL.), 50: 555-573.

Chang, S.Y. and D.S. Bai, 2001. Control charts for positively-skewed populations with weighted standard deviations. Qual. Reliabil. Eng. Int., 17: 397-406.

Chen, Y.K., 2004. Economic design of $\mathrm{X}^{-}$control charts for non-normal data using variable sampling policy. Int. J. Prod. Econ., 92: 61-74.

Choobineh, F. and J.L. Ballard, 1987. Control-limits of QC Charts for skewed distributions using weighted-variance. IEEE. Trans. Reliab., 36: 473-477. 
Dou, Y. and P. Sa, 2002. One-sided control charts for the mean of positively skewed distributions. Total Qual. Manage., 13: 1021-1033.

Khoo, M.B.C., A.M.A. Atta and C.H. Chen, 2009. Proposed $\mathrm{X}$ and $\mathrm{S}$ control charts for skewed distributions. Proceedings of the 2009 IEEE International Conference on Industrial Engineering and Engineering Management, December 8-11, 2009, IEEE, Hong Kong, China, pp: 389-393.

Khoo, M.B.C., A.M.A. Atta and Z. Wu, 2009. A multivariate synthetic control chart for monitoring the process mean vector of skewed populations using weighted standard deviations. Commun. Stat. Simul. Comput., 38: 1493-1518.

Nichols, M.D. and W.J. Padgett, 2006. A bootstrap control chart for Weibull percentiles. Quality Reliabil. Eng. Int., 22: 141-151.
Teh, S.Y., M.B.C. Khoo, K.H. Ong and W.L. Teoh, 2014. Comparing the Median Run Length (MRL) Performances of the Max-EWMA and Max-DEWMA control charts for skewed distributions. Proceedings of the 2014 International Conference on Industrial Engineering and Operations Management, January 7-9, 2014, Bali, Indonesia, pp: 1080-1087.

Tsai, T.R., 2007. Skew normal distribution and the design of control charts for averages. Int. J. Reliab. Qual. Saf. Eng., 14: 49-63.

Wu, Z., 1996. Asymmetric control limits of the x-bar chart for skewed process distributions. Int. J. Qual. Reliab. Manage., 13: 49-60.

Yourstone, S.A. and W.J. Zimmer, 1992. Non-normality and the design of control charts for averages. Decis. Sci., 23: 1099-1113. 